\title{
Open mitral valvotomy: fourteen years' experience
}

\author{
P H KAY, P BELCHER, K DAWKINS, S C LENNOX \\ From Brompton Hospital, London and St Mary's Hospital, London
}

SUMMARY During the period 1968 to 1980,222 patients with mitral valve disease in which stenosis was the dominant lesion were admitted under the care of the senior author. All patients presented with severe dyspnoea (NYHA grades 3 or 4). One hundred and fifty seven (71\%) patients were treated by open mitral valvotomy. One patient died within 30 days of operation $(0.6 \%$ hospital mortality) and one suffered a transient cerebrovascular accident. One hundred and twenty four (70\%) patients were followed up for one to 14 years (mean 7.5 years). There were seven late deaths. Actuarial curves predict the $\mathbf{9 0 . 2 \%} 10$ year survival after open mitral valvotomy. Eight patients required mitral valve replacement for restenosis corresponding to $16 \%$ at 10 years. The remaining patients are in NYHA grades 1 and 2.

Conservation of the native valve is preferable to valve replacement in the management of mitral stenosis. A successful valvotomy allows more normal filling of the left ventricle compared with the relatively obstructive prosthetic valves. ${ }^{1}$ Valve replacement for mitral stenosis is associated with an operative mortality of $5 \%,{ }^{2}$ while the incidence of subsequent thromboembolic complications ranges from 2 to $6 \%$ per patient per year. ${ }^{3-5}$

Closed mitral valvotomy is performed as a blind intracardiac procedure on a beating heart. It is associated with an operative mortality of between 2 and $7 \%$, 6-8 and an embolic rate of up to $8 \% .^{6-9}$ The uncertain anatomical result is associated with a high incidence of restenosis. ${ }^{7-13}$

Since the development of open mitral valvotomy in 1960 there have been numerous reports of improved results using this technique. ${ }^{14-18}$ Inspection of the mitral valve enables the suitability for open valvotomy to be assessed, while a better anatomical result can be obtained by direct visualisation of the valve and subvalvar apparatus. In addition, the functional result may be assessed at the time of operation. ${ }^{19-21}$

We report the results of open mitral valvotomy in 157 patients and show that this is a safe operation with a good long term prognosis.

\section{Subjects and methods}

During the period 1968 to 1980 patients with mitral

Accepted for publication 3 February 1983 valve disease in which stenosis was the dominant lesion were admitted under the care of the senior author (SCL). One hundred and fifty seven $(71 \%)$ of these patients were treated by open mitral valvotomy alone. The average age of these patients was 39 years (range 10 to 71 years). There was a female predominance of the order of $4: 1$.

All patients presented with severe restriction of exercise tolerance (NYHA grades 3 and 4). Eighty four (53\%) patients were in sinus rhythm. Seventeen (9\%) patients had suffered systemic emboli (12 cerebral, four femoral, and one mesenteric) of whom 15 were in atrial fibrillation. Eleven patients had previously undergone one, and five patients two closed mitral valvotomies between one and 24 years previously (mean nine years).

Between 1968 and 1972 patients were assessed for surgery almost entirely on a clinical basis. After 1972 M-mode echocardiography was used routinely to assess the mitral valve, and in 1978 this was supplemented by cross-sectional echocardiography. This latter investigation enables the mobility of the valve leaflets to be visualised indirectly in the beating heart and appears to be useful in predicting those patients who are suitable for valvotomy. ${ }^{22}$ The final decision between valvotomy and valve replacement, however, was made after direct visualisation of the valve at operation.

SURGICAL TECHNIQUE

In all cases the heart was exposed via a median sternotomy incision. Cardiopulmonary bypass was estab- 
lished with cannulation of the ascending aorta and both cavae. Before 1978 the operation was performed under moderate hypothermia, with the aorta clamped. Thereafter, cold cardioplegia was used to provide additional myocardial protection. The mitral valve was exposed by a vertical incision in the left atrium. If necessary, this was extended backwards under the inferior vena cava to improve exposure of the valve.

Twenty patients had thrombus removed from the left atrium. The left atrial appendage was not excised or excluded in any of the patients (other than those in whom it had been previously ligated at the time of closed mitral valvotomy).

Attention was then turned to the mitral valve. The decision to perform a valvotomy was based on the pliability of the valve tissue and the ability of the leaflets to coapt, producing a competent valve. The commissures were opened by sharp dissection with a scalpel. Great care was taken to avoid division of the chordae. This was facilitated by the use of traction sutures in the valve leaflets, allowing full exposure of the subvalvar apparatus. With the leaflets fully open the chordae were then separated by sharp dissection, if necessary extending the incision into the papillary muscle. Having mobilised the leaflets and shown their ability to coapt, it was essential that they should be pliant. Thirty eight (25\%) patients underwent decalcification of the valve leaflets in order to improve their pliability.

At the start of this series we attempted to perform an open valvotomy on all patients with mitral stenosis. After 1970 this approach was modified. Thirty three patients with heavily calcified valves producing a fixed eccentric orifice underwent immediate valve replacement. Open mitral valvotomy was attempted in 159 $(83 \%)$ patients. One hundred and fifteen were thought to have a good anatomical result, while a functional assessment of the competence of the valve was made in the remaining 44 patients. A left ventricular vent catheter was inserted through the apex and normal saline injected under pressure using a Canny-Riles syringe. Twelve patients had a trivial degree of regurgitation and no further procedure was performed. Thirty-two patients had significant regurgitation. In 17 patients an acceptable result was achieved after additional mitral valve annuloplasty. The remaining 15 patients underwent mitral valve replacement.

FOLLOW-UP

Thirty two patients returned to their country of origin and consequently their follow-up is incomplete. They have been excluded from further analysis. The remaining $124(79 \%)$ patients have been followed annually at the Brompton Hospital for one to 14 years (mean 7.5 years). Post mortem examinations have been performed on those patients who died.

\section{STATISTICAL ANALYSIS}

Only those patients undergoing open valvotomy alone have been analysed. The actuarial method ${ }^{23}$ was used to calculate survival and the rate of recurrent stenosis requiring valve replacement. Ninety-five per cent of confidence limits were determined by the Greenwood formula. ${ }^{24}$

\section{Results}

\section{MORTALITY}

The only hospital death in the series occurred in 1972 when a 65 year old woman who presented with gross pulmonary oedema died of low output cardiac failure on the second postoperative day.

Seven late deaths occurred in the series. Six patients died of congestive cardiac failure and one died after a cerebrovascular accident. The average age of these patients was 64 . Thus the actuarial curve predicts a $90.2 \%$ (95\% confidence limits $82.6 \%$ 97.8\%) 10 year survival after open mitral valvotomy (Fig 1).

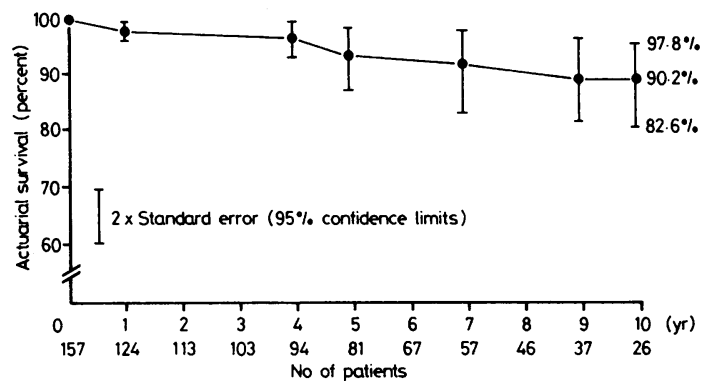

Fig. 1 Actuarial survival curve after open mitral valvotomy.

\section{PERIOPERATIVE EMBOLI}

One patient suffered a transient left hemiparesis and subsequently made a full recovery. There were no other cases of systemic embolism.

\section{RESTENOSIS OF MITRAL VALVE}

Eight patients required mitral valve replacement for restenosis, between one and 10 years after open mitral valvotomy. Two of these occurred in the first five years after the operation. Actuarial curves predict that $14.8 \%(95 \%$ confidence limits $3.4 \%-26.2 \%)$ patients will have undergone mitral valve replacement for recurrent stenosis 10 years after open mitral valvotomy (Fig. 2).

MITRAL REGURGITATION

At the start of this series we attempted to perform an 


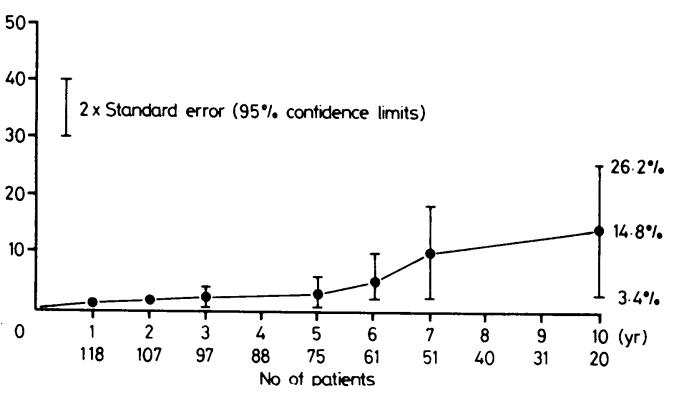

Fig. 2 Recurrent stenosis requiring mitral valve replacement after open mitral valvotomy.

open valvotomy on all patients with mitral stenosis. In the first three years, however, six of the 30 patients undergoing open mitral valvotomy clearly had an unsatisfactory result and required early valve replacement for excessive mitral regurgitation.

\section{LATE CEREBROVASCULAR ACCIDENTS}

Five patients suffered cerebrovascular accidents between one and eight years after operation $(0.7 \%$ per patient year). Four of these were in atrial fibrillation and receiving anticoagulant treatment. None of this group had thrombus present in the left atrium at the time of open valvotomy.

\section{CURRENT STATUS OF PATIENTS}

All surviving patients derived considerable benefit from the operation and are in NYHA grades 1 or 2 for exercise tolerance. Seventy three (59\%) patients in atrial fibrillation currently take digoxin, while thirty four patients require diuretics. It has been our policy to anticoagulate all patients in atrial fibrillation between the ages of 25 and 70 years.

\section{Discussion}

Preservation of the patient's own valve is highly desirable in the relief of mitral stenosis. In developed countries open mitral valvotomy had largely superseded the closed operation. ${ }^{15-18}$ The risk of cardiopulmonary bypass is now small, while the safety of aortic cross-clamping has been improved by the use of cold cardioplegic arrest. The bloodless operative field allows full inspection, anatomical dissection, and accurate débridement of the atrium, valve leaflets, and subvalvar apparatus. Valves unsuitable for a conservative procedure can be replaced at the same operation.

The low mortality $(0.6 \%)$ is similar to that of other series ${ }^{14-18}$ and compares favourably with the 2 to $7 \%$ mortality associated with closed mitral valvotomy ${ }^{6}$ and $5 \%$ for mitral valve replacement. ${ }^{2}$ Six of the seven late deaths were the result of congestive cardiac failure and all occurred in elderly patients.

One patient suffered a perioperative cerebrovascular accident and subsequently made a full neurological recovery. He had been in atrial fibrillation and there was a large amount of friable thrombus in the left atrium. This embolic rate of $0.6 \%$ is considerably better than the 2 to $8 \%$ reported for closed mitral valvotomy $^{6-9}$ and demonstrates another advantage of the open procedure: complete removal of intra-atrial thrombus.

Five patients suffered late cerebrovascular accidents, one of which was fatal. None of these patients had intra-atrial thrombus at the time of open mitral valvotomy.

Our experience with closed mitral valvotomy, using the Tubbs dilator initially set at $3.5 \mathrm{~cm}$ to prevent tearing of the leaflets, has been that only one commissure was split satisfactorily. Further expansion of the dilator then resulted in stretching of the valve ring, rather than splitting of the second commissure. Fig. 3 shows a mitral valve excised nine years after closed mitral valvotomy and is typical of many valves removed after this procedure. Complete fusion of the posteromedial commissure suggests that it was unlikely to have been split at closed valvotomy. The asymmetrical leaflet movement produced by unilateral splitting results in a turbulent flow which may be an important factor in the rate of recurrent stenosis.

In his Hunterian Lecture, Belcher ${ }^{11}$ suggests that "re-stenosis is inevitable after mitral valvotomy and that only the time taken for it to occur is variable". In our series only eight patients required mitral valve replacement for recurrent stenosis, corresponding to

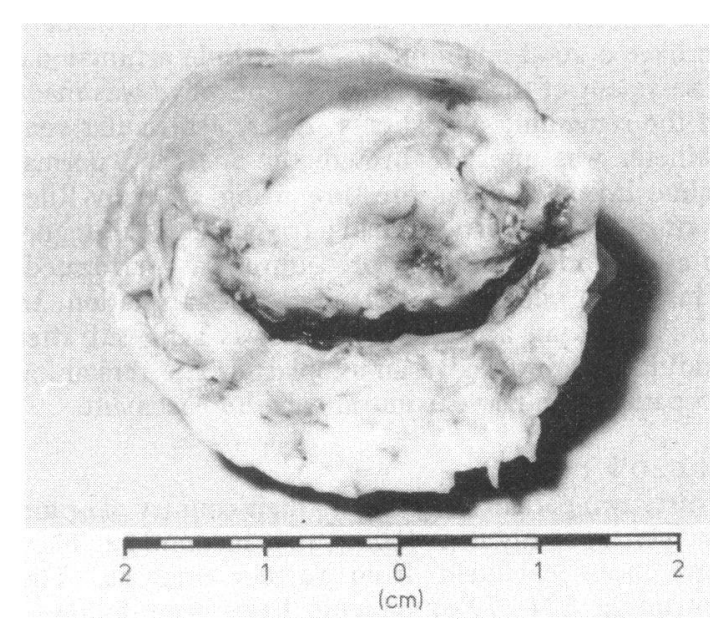

Fig. 3 Mitral valve excised nine years after closed mitral valvotomy. 
an actuarial figure of $14.8 \%$ (confidence limits $3.4 \%$ $26.6 \%$ ) at 10 years. Thus, the interval between open mitral valvotomy and gignificant restenosis does indeed appear to be profonged compared with the closed procedure. ${ }^{7-11}$ In those valves requiring late replacement for recurrent stenosis, the obstruction was the result of thickening and lack of mobility of the valve leaflets, rather than fusion of the commissures. Thus, they were not suitable for further valvotomy. In addition to the ability of the leaflets to coapt, their pliability is an important feature in the long term prognosis. Indeed, both patients requiring early mitral valve replacement for restenosis had non-pliant cusps at the time of open valvotomy.

One of the possible criticisms of the open approach to mitral valvotomy has been that too many valves are replaced. In this series $157(71 \%)$ patients with mitral valve disease in which stenosis was the dominant lesion were treated by open mitral valvotomy. In a further $17(8 \%)$ cases the native valve was salvaged by a combination of open mitral valvotomy and mitral valve annuloplasty. We have stressed that the ability of the valve leaflets to coapt and their pliability are important factors in the determination of long term success after open mitral valvotomy. Unsuitable valves tend to be those with a fixed eccentric orifice requiring extensive plastic procedures to the cusps, chordae, and annulus in an attempt to achieve a successful result. In this situation we have found mitral valve replacement to be more satisfactory.

\section{References}

1 Sutton M St J, Roudaut R, Oldershaw P, Bricaud, H. Echocardiographic assessment of left ventricular filling characteristics after mitral valve replacement with the St. Jude medical prosthesis. Br Heart f 1981; 45: 365-8.

2 Kirklin JW, Pacifico AD. Surgery for acquired valvular heart disease. Part 2. N Engl f Med 1973; 288: 194-9.

3 Macmanus Q, Grunkemeier GL, Lambert LE, Starr A. Non-cloth-covered caged-ball prostheses. The second decade. F Thorac Cardiovasc Surg 1978; 76: 788-94.

4 Björk VO, Henze A. Ten years' experience with the Björk-Shiley tilting disc valve. F Thorac Cardiovasc Surg 1979; 78: 331-42.

5 Oyer PE, Stinson EB, Reitz BA, Miller DC, Rossiter SJ, Shumway NE. Long-term evaluation of the porcine xenograft bioprosthesis. $\mathcal{F}$ Thorac Cardiovasc Surg 1979; 78: $343-50$.

6 Bakoulas G, Mullard K. Mitral valvotomy and embolism. Thorax 1966; 21: 43-6.
7 Belcher JR. Restenosis of the mitral valve: an account of 50 second operations. Lancet 1960; i: 181-4.

8 Hoeksema, TD, Wallace RB, Kirklin JW. Closed mitral commisurotomy: recent results in 291 cases. Am $\mathcal{F}$ Cardiol 1966; 17: 825-8.

9 Aronstam EM, Geiger JP, Gillespie JT. Reoperation for mitral stenosis. F Thorac Cardiovasc Surg 1968; 55: 7835.

10 Baker C, Hancock WE. Deterioration after mitral valvotomy. Br Heart f 1960; 22: 281-94.

11 Belcher JR. Restenosis of the mitral valve. Ann $R$ Coll Surg Engl 1979; 61: 258-64.

12 Dekker A, Black $H$, von Lichtenberg F. Mitral valve restenosis: a pathologic study. $\mathcal{F}$ Thorac Cardiovasc Surg 1968; 55: 434-46.

13 Logan A, Lowther CP, Turner RWD. Reoperation for mitral stenosis. Lancet 1962; i: 443-9.

14 Finnegan JO, Gray DC, MacVaugh H III, Joyner CR, Johnson J. The open approach to mitral commissurotomy. F Thorac Cardiovasc Surg 1974; 67: 75-82.

15 Halseth WL, Elliott DP, Walker EL, Smith EA. Open mitral commissurotomy. A modern re-evaluation. $\mathcal{f}$ Thorac Cardiovasc Surg 1980; 80: 842-8.

16 Housman LB, Bonchek L, Lambert L, Grunkemeier G, Starr A. Prognosis of patients after open mitral commissurotomy. Actuarial analysis of late results in 100 patients. $\mathcal{F}$ Thorac Cardiovasc Surg 1977; 73: 742-5.

17 Mullin MJ, Engelman RM, Isom OW, Boyd AD, Glassman E, Spencer FC. Experience with open mitral commissurotomy in 100 consecutive patients. Surgery 1974; 76: 974-82.

18 Roe BB, Edmunds LH Jr, Fishman NH, Hutchinson JC. Open mitral valvulotomy. Ann Thorac Surg 1971; 12: 483-91

19 Halseth WL, Elliot DP, Walker EL. Simplified intraoperative technique to test mitral valve repair. $\mathcal{F}$ Thorac Cardiovasc Surg 1980;80: 792-3.

20 King H, Csicsko J, Leshower A. Intraoperative assessment of the mitral valve following reconstructive procedures. Ann Thorac Surg 1980; 29: 81-3.

21 Pagliero KM, Yates AK. Peroperative assessment of mitral valve function. $\mathcal{F}$ Thorac Cardiovasc Surg 1972; 63: $458-460$.

22 Schweizer P, Bardos P, Krebs W, et al. Morphometric investigations in mitral stenosis using two dimensional echocardiography. Br Heart $\mathcal{F}$ 1982; 48: 54-60.

23 Grunkemeier GL, Starr A. Actuarial analysis of surgical results. Ann Thorac Surg 1977; 24: 404-408.

24 Cutler SJ, Ederer F. Maximum utilisation of the life table method in analysing survival. $f$ Chronic Dis 1958; 8: 699-712.

Requests for reprints to Mr P H Kay FRCS, London Chest Hospital, Bonner Road, London E2 9JX. 